\author{
International Journal of Innovative Research in \\ Electrical, Electronics, Instrumentation and Control Engineering
}

Vol. 9, Issue 12, December 2021

DOI: 10.17148/IJIREEICE.2021.91201

\title{
FABRICATION OF HYBRID COMPOSITES ON RICE HUSK ASH REINFORCED WITH Al ALLOY COMPOSITE
}

\author{
Sivaraman $\mathbf{S}^{1}$, Kalaikovan $\mathbf{M}^{2}$, Muthumari $\mathbf{M}^{3}$, Mohamed Javeeth $\mathbf{A}^{4}$, Aslam $\mathbf{M}^{5}$ \\ ${ }^{1}$ Assistant Professor - Aeronautical Engineering, Hindusthan College of Engineering and Technology, \\ Coimbatore, Tamilnadu. \\ 2,3,4,5 UG - Aeronautical Engineering, Hindusthan College of Engineering and Technology, Coimbatore, Tamilnadu.
}

\begin{abstract}
The most promising materials in today's engineering environment are light weight hybrid composites. They have a high strength-to-weight ratio and are used in variety of industries, including aviation and automobiles. When the chose reinforcements are cost-effective, the production of these prospective hybrid composites is less expensive. Aluminum alloy, rice husk, and silicon carbide were used as composite materials. Fabrication of composite materials has been completed. The hardness of several combinations of Aluminum, Silicon, and Rice husk ash reinforcements was investigated in fabricated metal matrix composites. As the content of rice husk and $\mathrm{SiC}$ increases, the shear strength of Al Composites improves. These composites can be employed anywhere lightweight materials with good stiffness and strength are required, resulting in low-cost aluminum.
\end{abstract}

\section{INTRODUCTION}

A composite material is a macroscopic blend of two or more different materials with a noticeable interface. Composites are employed in a variety of applications, including structural, electrical, thermal, and environmental. Modern composite materials are typically tailored to attain a specific balance of attributes for a specific application range. It's difficult to agree on a single, basic, and meaningful description given the wide range of materials that might be deemed composites and the wide range of functions for which composite materials can be produced. Composite materials, on the other hand, may be defined as materials that have a continuous matrix constituent that binds together and forms an array of stronger, stiffer reinforcing constituents. Many methods for preventing delamination have been discovered, for example, weaving the fibers increases toughness but introduces micro-buckling modes, which is detrimental to compressive strength; toughening the resin suppresses delamination but often reduces modulus, which is an inherent trade-off in increasing toughness in resins. Delamination occurs more frequently than not in mixed opening and shearing modes, which is the focus of this research. This research builds on the work of Darrin Haugen and Robert Morehead, who investigated delamination of the skin-stiffener junction geometry found in composite materials structures such as wind turbine blades.

\section{COMPOSITE MATERIALS}

Composite Materials are increasingly being used in the construction of military vehicles, sports equipment, and commercial buildings. There are two levels to which composites are generally classed. The matrix constituent is typically used to classify the initial level of categorization. Organic-matrix composites, metal-matrix composites, and ceramicmatrix composites are the three main types of composite. Particulate reinforcements, whisker reinforcements, continuous fiber laminated composites, and woven composites are the reinforcing forms classified at the second level. A significant volume fraction (10 percent or more) of reinforcement is required to offer a useful enhancement in characteristics.

\section{MATERIALS SELECTION}

\begin{abstract}
Aluminium alloy (Al6061)
It serves as a holding matrix for the reinforcement. Copper could be used in the $\mathrm{Al}$ alloy for this inquiry (4.5 percent wt). They are low in weight and resistant to corrosion. It has a melting point of 660 degrees Celsius. Automobile gearbox cases, pump parts, Aeroplane fittings, and control parts are all examples of where it's used. This alloy's unique features include excellent castability and weldability.

Engineering buildings employ aluminium alloys with a wide range of characteristics. Alloy systems are categorized using a numbering system or names that identify the primary alloying ingredients. Tensile strength, density, ductility, formability, workability, weldability, and corrosion resistance are just a few factors to consider when choosing the proper
\end{abstract}




\section{International Journal of Innovative Research in \\ Electrical, Electronics, Instrumentation and Control Engineering}

Vol. 9, Issue 12, December 2021

\section{DOI: 10.17148/IJIREEICE.2021.91201}

alloy for a specific application. Because of its excellent strength-to-weight ratio, aluminium alloys are commonly employed in aeroplanes. Pure aluminium metal, on the other hand, is far too soft for such applications, and it lacks the tensile strength required for planes and helicopters. When compared to unreinforced alloys, aluminium alloys reinforced with particles have better mechanical properties, hence reinforcements are good options for engineering applications.

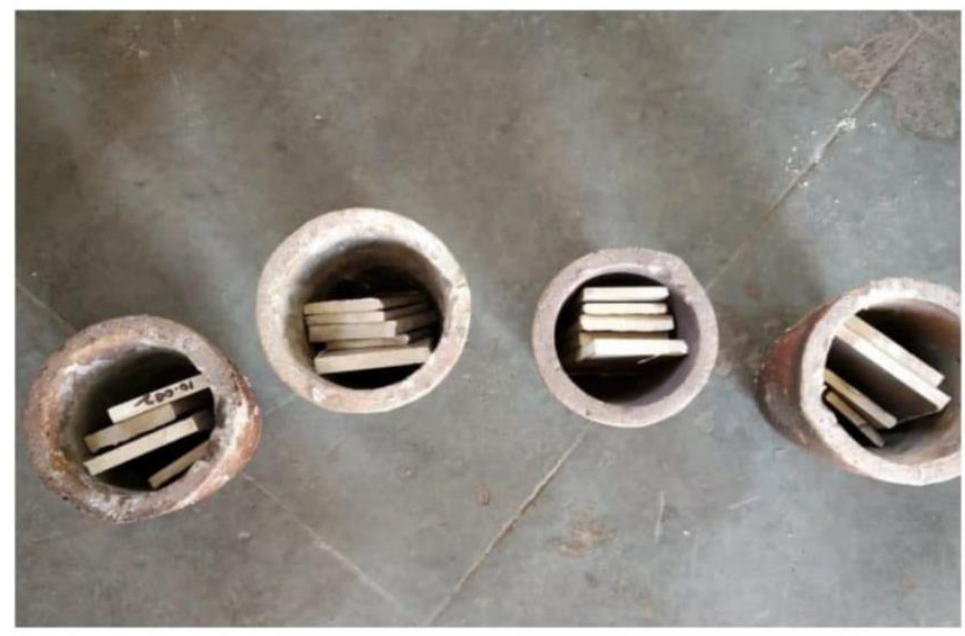

\section{Rice Husk Ash (RHA)}

Aluminum Alloy 6061

Rice husk ash is produced by burning rice hulls. This ash could be a source of amorphous reactive silica, which can be used in a range of materials science applications. The majority of the ash is used to make Portland cement. When completely burned, the ash can have a Blaine number of up to 3600 , which is much higher than the Blaine number of cement, indicating that it is finer than cement. The basic component of sand is silica, which is combined with cement for plastering and concreting. This fine silica will produce a concrete that is extremely compact. In addition, ash is an excellent thermal insulator. Because of its fineness, ash is an excellent candidate for sealing fine cracks in civil structures, where it can penetrate deeper than a traditional cement sand mixture.

Rice husk is an agricultural waste product that accounts for $20 \%$ of the world's yearly rice production of 649.7 million tonnes. Due to variances in paddy type, crop year, climate, and geographical factors, the chemical composition of rice husk varies from one sample to the next. Burning the husk at a temperature below $800 \mathrm{oC}$ can result in ash containing mostly amorphous silica.

Between 50 and 60 microns of rice husk ash were used. RHA particles dispersed well in the aluminium matrix, improving the matrix's hardness as well as the composite's tensile properties. The interfacial area between the matrix material and the RHA particles is enhanced, resulting in a significant improvement in strength.

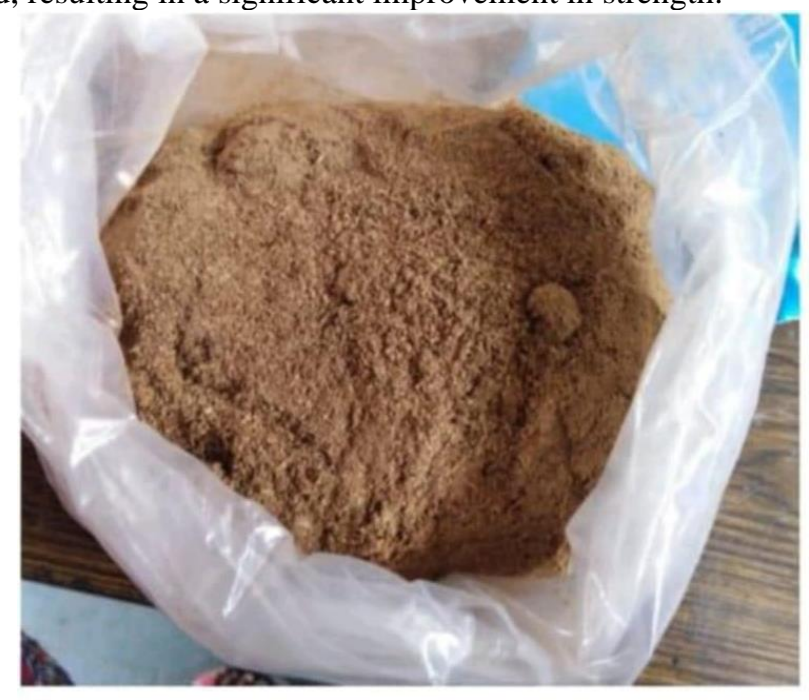

RICE HUSK ASH 


\section{International Journal of Innovative Research in \\ Electrical, Electronics, Instrumentation and Control Engineering}

Vol. 9, Issue 12, December 2021

DOI: $10.17148 /$ IJIREEICE.2021.91201

Silicon carbide $(\mathrm{SiC})$

$\mathrm{SiC}$ has a high thermal conductivity, a low thermal expansion, and is resistant to thermal shock. The SiC employed in this study is a hard-frequency material with particles smaller than 20 microns in size.SiC is a semiconductor material that is used in semiconductor electronic devices that operate at high temperatures, voltages, or both. The Lely method can be used to grow large single crystals of silicon carbide, which can then be cut into synthetic moissanite gems. SiO2 in plant material can be used to make $\mathrm{SiC}$ with a large surface area.There are around 250 different crystalline forms of silicon carbide. Polytypes are a vast range of comparable crystalline forms that characterise silicon carbide polymorphism. They are two-dimensional versions of the same chemical substance that differ in the third dimension.

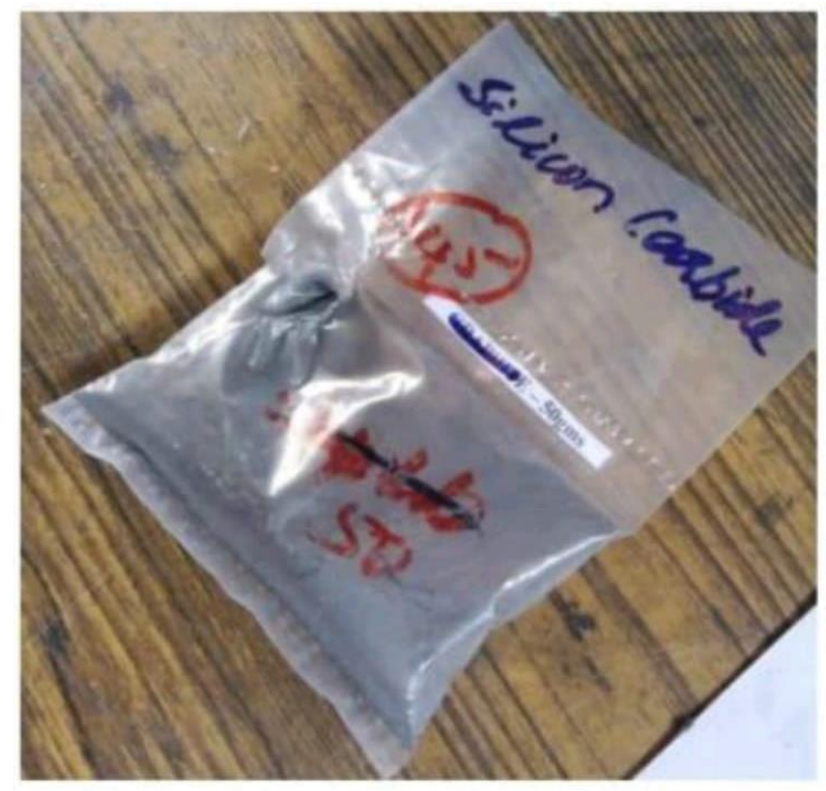

\section{SILICON CARBIDE}

\section{FABRICATION PROCESS STIR CASTING METHOD}

The twofold stir-casting procedure was employed to create the metal matrix composite that was used in this investigation. Bus bars of conductivity grade copper were used to obtain commercially pure aluminium $(99.95$ percent $\mathrm{Cu})$. At $730^{\circ} \mathrm{C}$, pure aluminium cut ingots were melted in an electric heating resistance furnace in a clay graphite crucible. A unique covering agent, Coverall ( $0.1 \mathrm{wt}$. percent of metal), is utilised to prevent excessive oxidation of the metal.

At $800^{\circ} \mathrm{C}$, copper chunks wrapped in aluminium foil were introduced to the aluminium melt, which was kept at that temperature until the copper entirely melted. After the furnace temperature was decreased to $750^{\circ} \mathrm{C}$, magnesium in the form of thin slices wrapped in aluminium foil was added to the Al-Cu alloy melt. Magnesium oxidation was reduced by sinking the slices into the melt's bottom and allowing them to melt on their own. A tiny amount of Coverall was added to the melt after it had been thoroughly stirred with a double stirrer for homogeneity in the composition. To keep the slurry semisolid, the furnace temperature was reduced to just below the liquid us at $5000 \mathrm{c}$. The warmed rice husk ash particles were manually stirred into the slurry using grates. The composite slurry was re-heated (7000c) to a fully liquid condition after sufficient human mixing, and then automatic mechanical mixing was carried out for around 20 minutes at an average stirring rate of $150 \mathrm{rpm}$. The furnace's temperature was gradually reduced at regular intervals.

\section{Composite making}

Stir casting was used to create the composite. In a pit furnace, $1.2 \mathrm{~kg}$ of $\mathrm{Al}$ was charged into a graphite crucible and melted to $660 \mathrm{oC}$. About $15 \mathrm{gm}$ of magnesium was added to the melt as a wetting agent between the matrix and reinforcement as the metal melted. It reduces both the casting fluidity and the surface tension of the molten aluminium. 


\section{IJIREEICE}

\section{International Journal of Innovative Research in Electrical, Electronics, Instrumentation and Control Engineering}

Vol. 9, Issue 12, December 2021

\section{DOI: 10.17148/IJIREEICE.2021.91201}

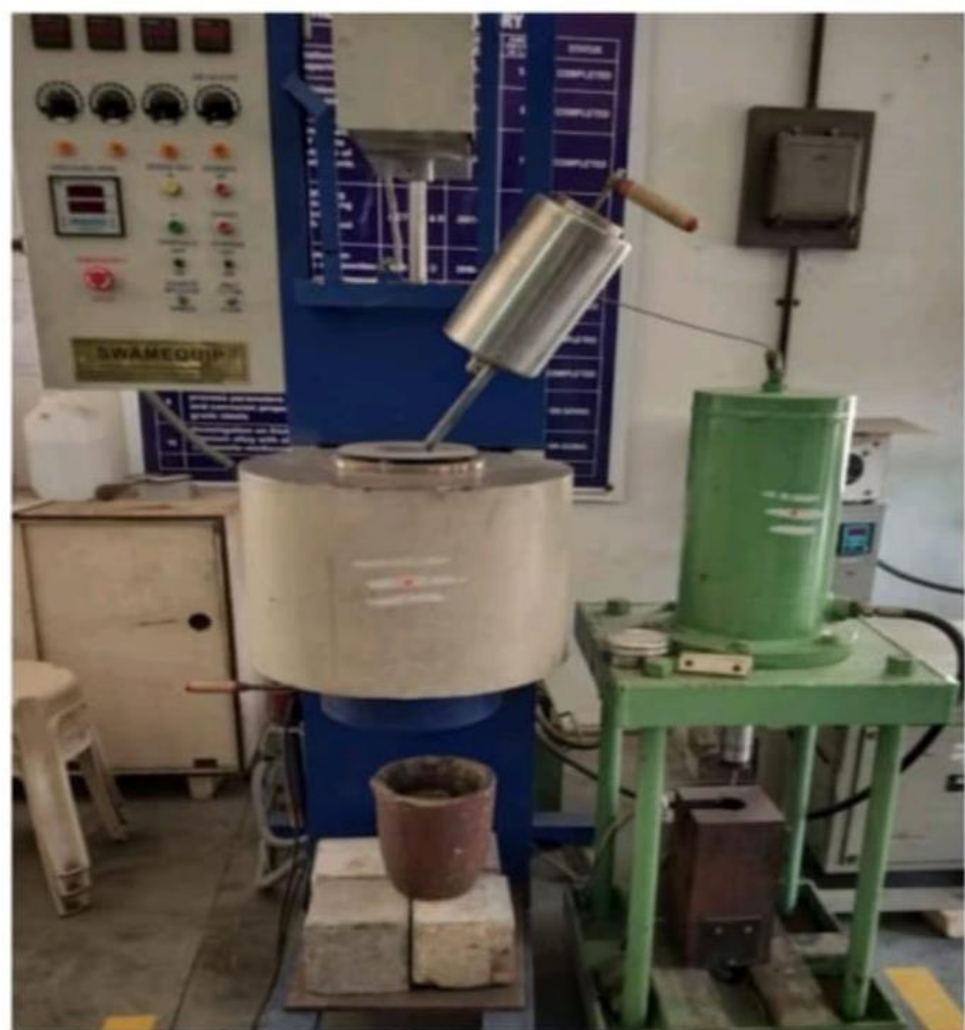

\section{STIR CASTING SETUP}

The molten aluminium was then transferred to the stir casting apparatus's holding furnace. The silica concentration of RHA particles was kept amorphous below $800 \mathrm{oC}$ by heating them to $700 \mathrm{oC}$ for 1 hour. To form a vortex, the graphite stirrer was dropped into the melt and stirred at 500rpm. To ensure uniform distribution, the preheated RHA was slowly added to the melt at the side of the vortex. After adding the reinforcement, the stirring was continued for another 7-8 minutes to ensure optimum particle distribution and mixing. The mixture was poured into a mild steel permanent mould that had been preheated to achieve uniform solidification of the casting at a temperature of 700oC. RHA reinforced $\mathrm{Al}$ matrix composites were created via this technique.

\section{Fabrication}

\section{Fabrication process of Rice Husk}

Rice husk was obtained, rinsed in water to eliminate dust, and then dried. Rice husk is typically dried at room temperature to ensure its viability for future operations. Normally, no chemical properties are altered in this area. Only dust and other non-essential materials are eliminated in preparation for the next steps.

The rice husk is first rinsed and dried before being placed in a graphite crucible. The washed rice husk was then heated to $200^{\circ} \mathrm{C}$ for one hour using the suitable arrangement of furnace and graphite crucible. Moisture and organic debris are removed during this procedure. Because of the caring of biological particles, the color of the husk changed from yellowish to black throughout this operation.

After heating the rice husk at $200^{\circ} \mathrm{C}$, the ash was heated again for 6 hours at $600^{\circ} \mathrm{C}$ to $800^{\circ} \mathrm{C}$ to remove the carbonaceous particles. The rice husk is entirely burned in the presence of oxygen during this process. The ash is then heated to $750^{\circ} \mathrm{C}$ in an electrical furnace to get the necessary characteristics. Rice husk ash is utilized as a filler material in this recipe. After this operation is completed and the ash has cooled, the color of the ash has entirely changed from black to grey or slightly greyish white.

\section{Specimen preparation for analysis}

The following are the varied compositions of composites mostly made by RHA, SiC, and Al6061:

The following are the varied compositions found in each specimen:

Specimen 1: This specimen is made of the aluminium alloy Al6061.

Specimen 2:Aluminum alloy Al6061 is manufactured with 1\% RHA and 2\% SiC. 


\section{International Journal of Innovative Research in Electrical, Electronics, Instrumentation and Control Engineering}

Vol. 9, Issue 12, December 2021

\section{DOI: 10.17148/IJIREEICE.2021.91201}

Specimen 3:Aluminum alloy Al6061 with 2 percent RHA and 1 percent SiC is manufactured. Specimen 4:Aluminum alloy Al6061 with 1 percent RHA and 4 percent $\mathrm{SiC}$ is fabricated.

\begin{tabular}{|l|l|l|l|}
\hline Specimen ID & RHA Quantity & SiC Quantity & $\begin{array}{l}\text { Aluminium } \\
\text { Quantity (gm) }\end{array}$ \\
\hline 1 & Nil & Nil & 500 \\
\hline 2 & $5 \mathrm{gm}(1 \%$ by wt) & 10 gm $(2 \%$ by wt $)$ & 500 \\
\hline 3 & 10 gm $(2 \%$ by wt $)$ & 5 gm $(1 \%$ by wt $)$ & 500 \\
\hline 4 & 5 gm $(1 \%$ by wt $)$ & 20 gm $(4 \%$ by wt $)$ & 500 \\
\hline
\end{tabular}

\section{MATERIAL TESTING}

\section{IMPACT TEST (IZOD)}

The ASTM standard for determining the impact resistance of materials is Izod impact testing. A pivoting arm is raised to a specified height and then released (constant potential energy). The arm swings down, slamming into the sample and shattering it. The sample's energy absorption is calculated using the height at which the arm swings after hitting the sample. To assess impact energy and notch sensitivity, a notched sample is commonly utilized.

The test is similar to the Charpy impact test, but the specimen under test is arranged differently. The sample is held in a cantilevered beam configuration rather than a three-point bending configuration in the Izod impact test, which differs from the Charpy impact test. The test is named after Edwin Gilbert Izod (1876-1946), an English engineer who described it in a 1903 lecture to the British Association, which was later published in Engineering.

\section{Impact Testing machine}

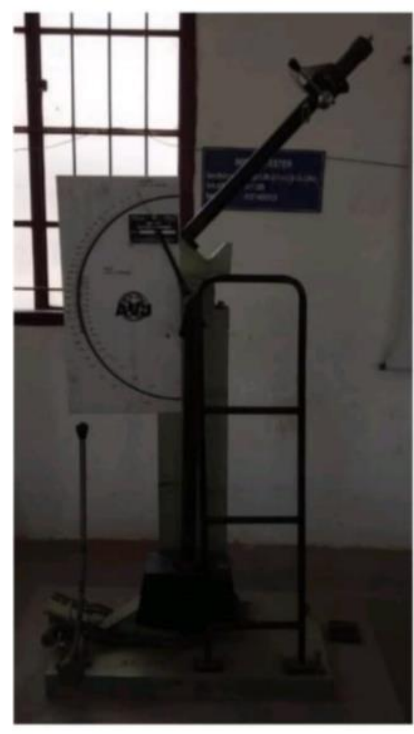

IMPACT TESTER

An impact tester can determine a material's toughness. For impact testing, notch type specimens are typically employed. The notch's function is to act as a stress concentrator. The impact energy of these hybrid composites was measured using an Izod impact testing machine. The length of the specimen was $75 \mathrm{~mm}$, the depth of the notch was $2 \mathrm{~mm}$, and the angle was 60o. The impact test determines the amount of energy that a substance can absorb. The majority of the testing specimens are constructed of Al alloy, which has a low hardness and good ductility. Therefore, to evaluate the absorbed energy, pendulum was set at the lowest position to get accurate values.

Impact strength $=($ Final scale reading - Initial scale reading $) / \mathrm{B}\left(\mathrm{D}-\mathrm{dg}_{\mathrm{s}}\right)$

Where;

$\mathrm{B}=$ Breadth of the specimen

$\mathrm{D}=$ depth of the specimen

$\mathrm{d}=$ depth of the groove 


\section{International Journal of Innovative Research in \\ Electrical, Electronics, Instrumentation and Control Engineering}

Vol. 9, Issue 12, December 2021

DOI: 10.17148/IJIREEICE.2021.91201

\section{IMPACT TEST (CHARPY)}

The Charpy Impact Test is the most often used test for evaluating how much force is absorbed by materials when they reach the point of fracture. This amount of energy is used to calculate the material's notch hardness

\section{DOUBLE SHEAR TEST}

Shear stress is defined as a shear force that acts on a specific area and is responsible for material deformation due to motion along a plane or a series of planes that are parallel to the applied stress. Shear stress can occur in either solid or liquid materials; in solid materials, it acts as a parallel force to the surface, whereas in liquids, it is related to fluid viscosity. Shear stress is always present when a beam is loaded, together with bending moment. In compression to bending stress, however, the effect of shear stress is minimal. However, when it comes to design calculations, the shear stress plays a crucial role because it is responsible for an object's collapse. Because the sample is loaded from both sides until it shears, this test is known as a double shear test.

\section{HARDNESS TEST}

In fabricated metal matrix composites (MMCs), the hardness of different combinations of $\mathrm{Al}$, SiC, and RHA reinforcements was tested. For assessing hardness, specimens were placed in a universal hardness testing machine (UHTM), which normally consists of a hydraulic system diamond ball indenter. The Brinell hardness number (BHN) is computed by multiplying the load in kilograms by the impressed area in square. Where L denotes the applied load, D denotes the load diameter in millimeters, and d denotes the impression diameter.

$\mathrm{L}$

$\mathrm{BHN}=$

$(\pi \mathrm{D} / 2)\left(\mathrm{D}-\left(\sqrt{ }\left(\mathrm{D}^{2}-\overline{\mathrm{d}^{2}}\right)\right)\right.$

Where;

BHN $=$ Brinell Hardness Number

$\mathrm{L}=$ Applied load

$\mathrm{D}=$ Diameter of the ball

$\mathrm{d}=$ Diameter of the impression

\section{Test Results}

SPECIMEN 1:

Composition - 500gm of Aluminium alloy

\begin{tabular}{|l|l|l|}
\hline S.NO & TYPES OF TESTS & RESULTS \\
\hline 1 & Impact (Charpy) & $3.375 \mathrm{~J} / \mathrm{mm}^{2}$ \\
\hline 2 & Impact(Izod) & $0.5 \mathrm{~J} / \mathrm{mm}^{2}$ \\
\hline 3 & Hardness(Brinell) & $49.7611 \mathrm{~kg} / \mathrm{mm}^{2}$ \\
\hline 4 & Double Shear(UTM) & $53.503 \mathrm{~N} / \mathrm{mm}^{2}$ \\
\hline
\end{tabular}

\section{SPECIMEN 2:}

Composition - 500gm of Aluminium alloy,5gm of RHA and $10 \mathrm{gm}$ of Sic

\begin{tabular}{|l|l|l|}
\hline SL.NO & TYPES OF TESTS & RESULTS \\
\hline 1 & Impact(charpy) & $3.25 \mathrm{~J} / \mathrm{mm}^{2}$ \\
\hline 2 & Impact(Izod) & $0.375 \mathrm{~J} / \mathrm{mm}^{2}$ \\
\hline 3 & Hardness(brinell) & $45.7875 \mathrm{~kg} / \mathrm{mm}^{2}$ \\
\hline 4 & Double shear(UTM) & $56 \mathrm{~N} / \mathrm{mm}^{2}$ \\
\hline
\end{tabular}

\section{SPECIMEN 3:}

Composition - 500gm of Aluminium alloy, $10 \mathrm{gm}$ of RHA and $5 \mathrm{gm}$ of Sic

\begin{tabular}{|l|l|l|}
\hline SL.NO & TYPES OF TESTS & RESULTS \\
\hline 1 & Impact (Charpy) & $3.125 \mathrm{~J} / \mathrm{mm}^{2}$ \\
\hline 2 & Impact(Izod) & $0.25 \mathrm{~J} / \mathrm{mm}^{2}$ \\
\hline 4 & Hardness(Brinell) & $45.7875 \mathrm{~kg} / \mathrm{mm}^{2}$ \\
\hline
\end{tabular}

\section{SPECIMEN 4:}

Composition - 500gm of Aluminium alloy,5gm of RHA and $20 \mathrm{gm}$ of Sic

\begin{tabular}{|l|l|l|}
\hline SL.NO & TYPES OF TESTS & RESULTS \\
\hline
\end{tabular}


International Journal of Innovative Research in

Electrical, Electronics, Instrumentation and Control Engineering

Vol. 9, Issue 12, December 2021

DOI: 10.17148/IJIREEICE.2021.91201

\begin{tabular}{|l|l|l|}
\hline 1 & Impact (Charpy) & $2.25 \mathrm{~J} / \mathrm{mm}^{2}$ \\
\hline 2 & Impact(Izod) & $0.25 \mathrm{~J} / \mathrm{mm}^{2}$ \\
\hline 3 & Hardness(Brinell) & $42.025 \mathrm{~kg} / \mathrm{mm}^{2}$ \\
\hline 4 & Double Shear(UTM) & $49.93 \mathrm{~N} / \mathrm{mm}^{2}$ \\
\hline
\end{tabular}

PROPORTIONS COMPARISON BETWEEN SPECIMENS:

\section{Charpy test:}

In a comparison of four specimens, specimen 2 (500gm Al alloy, 5gm RHA, and $10 \mathrm{gm} \mathrm{SiC})$ is more or less equal to specimen 1 (500gm Al alloy, $5 \mathrm{gm} \mathrm{RHA}$, and $10 \mathrm{gm} \mathrm{SiC})(500 \mathrm{gm}$ of $\mathrm{Al})$. When compared to specimen 2 , specimen $3 \& 4$ are quite little.

Izod test:

When comparing specimen $1(500 \mathrm{gm} \mathrm{Al})$ to specimen 2 (500gm Al alloy, 5gm RHA, and 10gm SiC), specimen 2 outperforms specimens $3 \& 4$.

\section{Hardness test:}

In this test, specimens $2 \& 3$ have the same hardness as specimen 1 , which is more or less the same. Specimen 4 has a lower hardness than the other specimens.

Double shear test:

Specimen 2 is more efficient than specimens 1, 3, and 4 when comparing the specimens. It is, in particular, greater than specimen 1.

\section{CONCLUSION}

Stir casting processes were used to successfully incorporate rice husk ash particles into Al6061 alloy. The homogeneous distribution of rice husk ash and Silicon carbide particles in the aluminium alloy is demonstrated by specimen test results. Increases in rice husk ash content increase the hardness of A16061/RHA composites. The shear strength of Al6061/RHA composites improves as the rice husk and $\mathrm{SiC}$ content rises. Hardness rises as the amount of rice husk ash and $\mathrm{SiC}$ concentration rises.

Rice husk ash content increases the toughness measured by impact test. And, according to the comparison, $1 \%$ RHA and $2 \% \mathrm{SiC}$ (Specimen 2) have an efficient outcome that is comparable to Al alloy (Specimen 1). Rice husk ash, a byproduct of paddy milling, has been effectively employed as a reinforcing material in the manufacture of Metal Matrix Composites (MMCs) components in an aluminium matrix. Thus, using RHA to make composites can turn agricultural waste into industrial wealth while also solving the problem of RHA storage and disposal. Rice husk ash particles incorporated into an aluminium matrix can result in low-cost aluminium composites with increased hardness and strength. Wherever lightweight materials with good stiffness and strength are required, these composites can be used.

\section{REFERENCES}

[1] P. B. Madakson, D. S. Yawas and A. Apasi, "Characterization of Coconut shell ash for potential utilization in metal matrix Composites for automotive applications", International Journal of Eng Sci Technology, vol. 3, no. 4, (2012), pp. 1190-8.

[2] P. Rohatgi, "Cast aluminum-matrix composites for automotive applications", JOM Journal of the Minerals, Metals and Materials Society, vol. 43, no. 4, (1991), pp. 10-15.

[3] S. R. Patil and B. S. Motgi, "A Study on Mechanical Properties of Fly Ash and Alumina Reinforced Aluminium Alloy (LM25) Composites", eISSN: 2278-1684, p-ISSN: 2320-334X, vol. 7, no. 6, (2013) July-August, pp. 41-46.

[4] H. Zuhailawati, P. Samayamutthirian, C.H. Mohd Haizu, J Phys Sci. 18, 47-55 (2007).

[5] K.K.Alanemea, B.O.Ademilua, M.O.Bodunrin, Tribol Ind. 35(1), 25-35 (2013

[6] Christy TV, Murugan N, Kumar S. A comparative study on the microstructures and mechanical properties of Al 6061 alloy and the MMC Al 6061/TiB2/12p. JMMCE. 2010;9:57-65.

[7] Miracle DB. Metal matrix composites - from science to technological significance. Compos Sci Technol. 2005;65: 526-40.

[8] Madakson PB, Yawas DS, Apasi A. Characterization of Coconut shell ash for potential utilization in metal matrix composites for automotive applications. IJEST. 2012;4:1190-8.

[9] Prasad SD, Krishna RA. Production and mechanical properties of A356.2/RHA composites. IJAST. 2011;33:51-8.

[10] Zuhailawati H, Samayamutthirian P, Mohd Haizu CH. Fabrication of low cost aluminum matrix composite reinforced with silica sand. J Phys Sci. 2007; 18:47-55.

[11] Alaneme KK. Mechanical behaviour of cold deformed and solution heat-treated alumina reinforced AA 6063 composites. J Eur Ceram Soc. 2013; $35(2): 31-5$.

[12] Alaneme KK. Mechanical behaviour of cold deformed and solution heat-treated alumina reinforced AA 6063 composites. J Eur Ceram Soc. 2013; $35(2): 31-5$

[13] Chawla N, Shen Y. Mechanical behaviour of particle reinforced metal matrix composites. Adv Eng Mater. 2001;3:357-70.

[14] Ranjbaran MM. Low fracture toughness in Al 7191-20\% SiCp aluminum matrix composite. Eur J Appl Eng Sci Res. 2010; 41:261-72. 